\section{Sport Medicine at its Peak}

\section{E Laura Cruz}

Welcome to the CASEM issue of BJSM! The Canadian Academy of Sport and Exercise Medicine is the only organisation in Canada dedicated to sport and exercise medicine physicians. Established almost 50 years ago, CASEM has been the leader in SEM education and training of new sport and exercise physicians throughout its existence.

In a typically Canadian manner, CASEM has quietly elevated itself, with all 850 or so members, to a well respected position on the international academic stage. Our members are leaders in epidemiology and injury prevention research, concussion consensus meetings, physical activity for health initiatives and as active participants in knowledge translation as editors, reviewers and authors. Our expert members are world renowned and too numerous to list here. One of them, Dr Jack Taunton, runner and teacher extraordinaire is teaching his unparalleled Running Injuries workshop 22 April 2017 in Vancouver. (http://casem-acmse.org/)

CASEM is enjoying being a member society of BJSM. We are learning a great deal about current knowledge translation trends-the use of podcasts, webinars, and social media. I am reminded with each new issue that I really do need a new phone

Correspondence to Dr E Laura Cruz, Canadian Academy of Sport and Exercise Medicine, 55 Metcalfe St, Ste 300, Ottawa, Ontario, Canada K1P6L5: drlaura@liveactivesportmed.com so that I can try all the apps that I read about! We are also invited to participate in ways that go beyond the numerous Canadians who support BJSM as editors and reviewers-through collaborative support of member societies' position papers and statements.

\section{'SPORT MEDICINE AT ITS PEAK'. OUR UPCOMING ANNUAL CONFERENCE}

Canadians are recognised for their friendliness, and hospitality and we also know how to enjoy our beautiful country in snow or sun. I invite you join us at our next CASEM Symposium 'Sport Medicine at its Peak'. Our annual conference will be returning to Quebec's beautiful Mont Tremblant, 7 to 10 June 2017. Well known as a ski destination, Tremblant offers hiking, bike trails and numerous other outdoor activities throughout the summer months.

This year's exciting programme will feature a review of the Berlin 5th International Consensus Conference on Sport Concussion; pearls from a Cirque du Soleil athletic therapist and updates on regenerative medicine. Each annual symposium is an opportunity for the local organising committee to showcase regional as well as national expertise-and many of our Quebec CASEM colleagues will take to the podium.

Enjoy this CASEM focused issue and perhaps the cover photo (figure 1) of

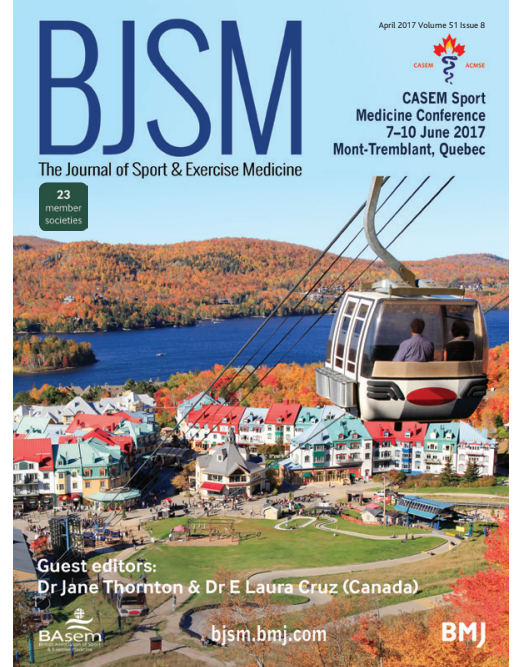

Figure 1 CASEM focused issue.

beautiful Mont Tremblant will inspire you to join us in June!

Until then! A bientot!

Competing interests None declared.

Provenance and peer review Commissioned; internally peer reviewed.

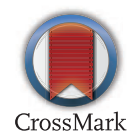

To cite Cruz EL. Br J Sports Med 2017;51:623.

Accepted 2 March 2017

Published Online First 7 March 2017

Br J Sports Med 2017:51:623.

doi:10.1136/bjsports-2017-097742

(C) Article author(s) (or their employer(s) unless otherwise stated in the text of the article) 2017. All rights reserved. No commercial use is permitted unless otherwise expressly granted. 